PRAXIS

ecucativa

Universidad Nacional de La Pampa

Facultad de Ciencias Humanas

Instituto de Ciencias de la Educación

para la investigación interdisciplinaria

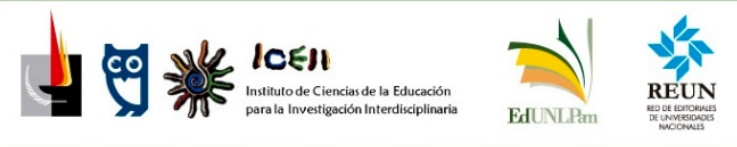

ISSN 2313-934X

SANTA ROSA, LA PAMPA, ARGENTINA

Correo electrónico: iceii@humanas.unlpam.edu.ar

Disponible en https://cerac.unlpam.edu.ar/index.php/praxis

La escuela ante el fracaso escolar en contextos de inequidad: entre mandatos sociales y respuestas medicalizadas. Artículo de Mariana Diez y Lucía de Pena. Praxis educativa, Vol. 26, No 1 enero - abril 2022. E - ISSN 2313-934X. pp. 1-18.

\title{
La escuela ante el fracaso escolar en contextos de inequidad: entre mandatos sociales y respuestas medicalizadas
}

The school in the face of school failure in contexts of inequity: between social mandates and medicalized responses

A escola face ao fracasso escolar em contextos de iniquidade: entre mandatos sociais e respostas medicalizadas

\author{
Mariana Diez \\ Universidad de la República, Uruguay \\ marianadiezx@gmail.com \\ ORCID 0000-0002-8995-8172

\section{Lucía de Pena} \\ Universidad de la República, Uruguay \\ ludepena@gmail.com \\ ORCID 0000-0002-9408-6460
}

Recibido: 2021-06-19 | Revisado: 2021-10 -09 | Aceptado: 2021-11-30 


\section{Resumen}

El presente artículo aborda el complejo y multideterminado problema del fracaso escolar en contextos de vulneración de derechos, aportando una lectura que retoma la innegable influencia que las condiciones de vida tienen en el desarrollo de las herramientas que sostienen los aprendizajes. Para ello, nos valemos de nuestra experiencia como profesionales de la salud que se desempeñan en el ámbito de la clínica psicomotriz y de la revisión de la bibliografía vinculada a la temática.

Si bien Uruguay ha realizado importantes esfuerzos en el campo de la educación inclusiva a través de la instalación de la temática en la agenda pública y de la sanción de leyes al respecto, la generación de las condiciones que aseguren el cumplimiento efectivo de los derechos consagrados tanto a nivel ético como jurídico resulta aún complejo.

Para aproximarnos a esta temática, nos interesa problematizar el modelo escolar hegemónico que ha caracterizado a la Modernidad, y analizar las respuestas fallidas que se construyen entorno al fracaso escolar en contextos de inequidad social, entre las que destacamos la medicalización de las dificultades escolares y los discursos que refuerzan la pretendida potencia igualadora de la escuela.

Palabras clave: derechos de infancia, políticas públicas, inclusión educativa, desigualdad social, fracaso escolar.

\section{Abstract}

This article addresses the complex and multi-determined problem of school failure in contexts of violation of rights, providing a reading that takes up the undeniable influence that living conditions have on the development of the tools that support learning. For this we take into account our experience as health professionals who work in the field of psychomotor clinic and the review of the literature related to the subject.

Although Uruguay has made important efforts in the field of inclusive education through the installation of the issue on the public agenda and the enactment of laws in this regard, the generation of conditions that ensure the effective fulfillment of the rights enshrined both at an ethical and legal level, it is still complex. To approach this issue we are interested in problematizing the hegemonic school model that has characterized Modernity, and analyzing the failed responses that are built around school failure in contexts of social inequity, among which we highlight the medicalization of school difficulties and discourses that reinforce the alleged equalizing power of the school.

Keywords: children's rights, public policies, educational inclusion, social inequality, school failure.

\section{Resumo}

Este artigo aborda a problemática complexa e multideterminada do fracasso escolar em contextos de violação de direitos, proporcionando uma leitura que retoma a inegável influência que as condições de vida exercem no desenvolvimento das ferramentas de apoio à aprendizagem. Para isso utilizamos nossa experiência como profissionais de saúde que atuam na área da clínica psicomotora e a revisão da bibliografia relacionada ao assunto.

Embora o Uruguai tenha feito importantes esforços no campo da educação inclusiva por meio da inserção do tema na agenda pública e da promulgação de leis a esse respeito, a geração de condições que garantam o efetivo cumprimento dos direitos consagrados tanto no plano ético quanto no jurídico. nível, ainda é complexo. 
Para abordar essa questão, interessa-nos problematizar o modelo escolar hegemônico que tem caracterizado a Modernidade, e analisar as respostas reprovadas que se constroem em torno do fracasso escolar em contextos de iniquidade social, entre as quais destacamos a medicalização das dificuldades e discursos escolares. alegado poder equalizador da escola.

Palavras-chave: direitos da criança, políticas públicas, inclusão educacional, desigualdade social, fracasso escolar.

Pero el saber no conlleva en sí mismo ninguna consecuencia igualitaria. La lógica de la Escuela republicana, que promueve la igualdad por la distribución de lo universal del saber, está también atrapada en el paradigma pedagógico que reconstituye indefinidamente la desigualdad que promete suprimir. (Rancière, 2007, p. 11)

\section{Introducción}

En el presente artículo, nos proponemos trabajar algunas consideraciones acerca de la inclusión educativa en el sistema escolar uruguayo, en especial el complejo y multideterminado problema del fracaso escolar en contextos de vulneración de derechos, aportando una lectura que retoma la innegable influencia que las condiciones de vida tienen en el desarrollo de las herramientas que sostienen los aprendizajes. A nivel nacional, las fuentes consultadas muestran la asociación entre el origen social de las personas y los resultados educativos que se obtienen, constatándose una alta prevalencia del fracaso escolar en las escuelas a las que concurren los niños, niñas y adolescentes provenientes de los sectores de la sociedad más pobres (ANEP, 2021).

Aun cuando no es el tema central de este trabajo, resulta relevante señalar que esta desigualdad educativa, consecuencia de la desigualdad social que caracteriza a nuestras sociedades, se ha visto profundizada en el contexto de la pandemia por COVID-19 (CEPAL y UNESCO, 2020; Dussel et al., 2020; Anderete Schwal, 2020).

Para comenzar consideramos importante destacar que el término inclusión puede hacer referencia a múltiples dimensiones. En este trabajo, nos referimos específicamente a la inclusión de niños y niñas que nacen y crecen en contextos sociales desfavorecidos y de vulneración de derechos, y que por ende ven comprometidas sus posibilidades de éxito escolar. Al respecto Kachinovsky y Gabbiani (2014) señalan que la inclusión educativa:

Alcanza hoy significados amplios pero precisos: que se haga efectiva la asistencia a la escuela de todos los que se encuentran en edad escolar, que los centros escolares garanticen la calidad del servicio brindado, que la formación sea compartida con otros sin que por ello anule las singularidades y la cultura local, ni codifique como única cultura autorizada la de algunos sectores sociales. (p. 37)

Si bien el país ha realizado importantes esfuerzos en el campo de la educación inclusiva, a través de la instalación de la temática en la agenda pública y de la sanción de leyes al respecto, la 
generación de las condiciones que aseguren el cumplimiento efectivo de los derechos consagrados tanto a nivel ético como jurídico resulta aún complejo, a partir de la generación de un escenario que opera en el registro del "como si", en la medida en que los discursos y las prácticas se distancian por brechas insalvables que, en definitiva, sostienen y profundizan las diferencias sociales, con las consecuencias negativas que se asocian al fracaso escolar como escenario de complejo análisis.

Nos interesa problematizar la prevalencia hegemónica del paradigma escolar de la Modernidad (Siglo XVIII) en la configuración del actual sistema educativo y la implementación de las políticas educativas. En este sentido, intentamos analizar cómo opera la configuración de la escuela actual al momento de implementar algunas políticas educativas.

A lo largo de la historia, se observa una tendencia de la institución escolar, en sus múltiples formatos, a moldear subjetividades de acuerdo con determinados supuestos e intereses, acotando aquellos rasgos que mejor definen al ser humano y a su desarrollo: lo indeterminado e imprevisible. Nos preguntamos, entonces: ¿cuál es el tratamiento que recibe la singularidad en los actuales contextos educativos?

En segundo lugar, planteamos una invitación a detenernos en el lenguaje vinculado este tema que circula cotidianamente en el ámbito educativo. Entendemos que parte de la tarea profesional implica revisar las representaciones y los discursos que en mayor o menor grado construimos y nos construyen, ideas naturalizadas de las que resulta difícil desmarcarse y que terminan condicionando fuertemente las prácticas educativas en uno u otro sentido. Los y las profesionales vinculados y vinculadas a la educación y a la salud nos encontramos desarrollando nuestra tarea en el marco de determinados límites materiales y simbólicos impuestos por la institución: reglas e ideas que nos anteceden y que han sido interiorizadas sin cuestionamientos, una praxis que corresponde debatir, condición imprescindible para su transformación. De esta manera, intentamos trabajar los sentidos con los que se enuncian determinados conceptos igualdad, diversidad, normalidad, inclusión- en el contexto escolar, aportando a la discusión de los posibles efectos en la tarea educativa, en el entendido que la retórica vacía no transforma la praxis. (Freire, 2011)

\section{Marcos interpretativos del problema del fracaso escolar}

El fracaso escolar es un tema complejo y de enorme pertinencia en el contexto educativo actual, tanto a nivel nacional como internacional, especialmente en el continente latinoamericano. Es un problema que ha acompañado al sistema educativo desde el aumento de la cobertura, a partir de la universalización de la educación básica y de la ampliación de los años de escolaridad obligatoria (Kachinovsky y Gabbiani, 2014; Terigi, 2009). Estas políticas educativas, orientadas a democratizar la educación, permitieron el ingreso al sistema de sectores de la sociedad anteriormente excluidos, situación que significó el rompimiento de la homogeneidad que caracterizaba al alumnado en términos de nivel socioeconómico y procedencia cultural. 
Desde el punto de vista conceptual, el término fracaso escolar ha sido definido por diferentes autores y autoras de manera similar, aunque con algunos matices. Así, en términos generales, el fracaso escolar puede ser entendido como el rendimiento académico por debajo de lo esperado para el grado escolar que se cursa, objetivable en cuestiones concretas como el ausentismo, la asistencia intermitente, el desfasaje importante respecto del nivel de conocimientos esperados, la repetición, la extraedad y la desafiliación educativa (Aristimuño, 2015; Lara-García et al., 2014; Escudero Muñoz, 2005).

Los principales puntos de tensión respecto de este problema se organizan en torno a la pregunta sobre quién o quiénes fracasan y por qué. La siguiente cita de Mafokozi (1991) pone en evidencia algunas de estas tensiones:

El "fracaso escolar" se presenta como uno de tantos términos polisémicos utilizados en Ciencias Sociales que sólo admiten ser definidos partiendo de una toma de postura previa. Si se adopta el contexto escolar como referencia del fracaso escolar se definiría como la incapacidad del alumno para cumplir los objetivos propuestos, explícitamente o no, por la escuela. Eligiendo el punto de vista del educando el fracaso escolar aparece como la incapacidad del alumno para alcanzar un cierto grado de satisfacción y autorrealización personal. En relación con la propia institución escolar el fracaso consiste en la impotencia de cumplir los objetivos sociales. En cualquier caso el elemento definitorio esencial es la incapacidad de conseguir el objetivo asignado por otros o por uno mismo. (p. 173)

Así, el fracaso escolar constituye un escenario de múltiples tensiones por ser la expresión de fenómenos muy complejos y multidimensionales. Las tensiones se evidencian cuando los discursos que intentan explicar los fenómenos operan con reduccionismos que inhabilitan la reflexión responsable, insistiendo en lecturas unívocas y lineales. Las voces que suenan con más fuerza hoy en día analizan estos fracasos fundamentalmente desde dos perspectivas: la individual y la institucional.

Por un lado, la perspectiva individual parte de la premisa de que los fracasos escolares son la expresión de las llamadas dificultades de aprendizaje. Las dificultades de aprendizaje primarias constituyen, por definición, una fragilidad en las funciones psicológicas superiores que posibilitan el aprendizaje escolar, con una etiología definida como neurobiológica (Rebollo, 2007). Las dificultades de aprendizaje secundarias constituyen también una fragilidad en las herramientas que posibilitan el aprendizaje escolar, aunque con una etiología muy diversa, entre las que se destacan como prevalente nacer y crecer en contextos de pobreza (Organización de Naciones Unidas, 2017).

Ambas, dificultades de aprendizaje, primarias y secundarias, se expresan en el ámbito educativo; sin embargo, su abordaje se resuelve, generalmente, en el ámbito sanitario. Las primarias no constituyen, en términos de prevalencia, la mayor preocupación, siendo las secundarias las que dominan el escenario y en las que nos vamos a centrar en esta oportunidad, fundamentalmente en las construidas en contextos de pobreza. 
Las dificultades de aprendizaje secundarias, a partir de una especialización del saber técnico acerca del desarrollo infantil, se constituyen gradualmente en objeto de intervención de diferentes disciplinas del campo de la salud. De este modo, estas dificultades pasan a nominarse desde una lógica sanitarista y medicalizada como trastornos, que cristalizan funcionamientos y dejan escaso margen para el análisis de las condiciones materiales concretas que operan obstaculizando la construcción de las herramientas del aprender.

En este sentido, el saber técnico disciplinar del campo de la salud profundiza su discurso acerca del fracaso escolar, delimitando una especificidad diagnóstica y terapéutica. Las dificultades se expresan cotidianamente en la escuela, no obstante, se diagnostican y se abordan a nivel sanitario. En palabras de Cristóforo y Achard (2017):

Este modelo desresponsabiliza a la educación y a los educadores, puesto que, si se trata de un problema de salud la solución-remedio no está en la educación sino en el diagnóstico realizado por un profesional externo a la misma, del que se esperan rápidamente soluciones para que el problema deje de existir. (p. 225)

Desde nuestra perspectiva clínica, interrogamos el aumento de los diagnósticos de dificultades de aprendizaje secundarias vinculadas a la pobreza infantil, haciendo recaer en el plano de lo individual la delimitación del problema, la comprensión del fenómeno y la respuesta posible. Nos interesa, especialmente, remarcar que esta perspectiva y las respuestas asociadas han demostrado ser empíricamente ineficientes en tanto no se logra una transformación franca de las herramientas del aprendizaje, ya que las condiciones que las sostienen persisten vulneradas, situación que se hace evidente en el análisis de las cifras que muestran que, en nuestro país, el fracaso escolar se encuentra estratificado, prevaleciendo de forma muy notoria en niños y niñas de los quintiles inferiores de la sociedad.

Asimismo, esta perspectiva demanda la consolidación de nuevos equipos técnicos que, supuestamente, generarían un marco de igualdad, en tanto posibilitarían a niños y niñas vulnerados y vulneradas el acceso a la atención en salud (es decir, el abordaje de lo que ha sido diagnosticado como trastorno). Las demandas del sistema educativo al sistema de salud se profundizan y multiplican, no como efecto de la problematización del aprendizaje en tanto campo de intersección de saberes, sino como búsquedas más o menos erráticas de dispositivos para paliar los efectos de la expresión de la inequidad en el sistema educativo. Dicen al respecto Cristóforo y Achard (2017) que: "La alta demanda de los docentes de que sea diagnosticado y medicado lo diferente, se ha configurado como un síntoma social que, como todo síntoma, encubre y disimula las condiciones de producción del mismo" (p. 227).

A partir de estas demandas, en el mejor de los casos, los equipos técnicos se multiplican; sin embargo, al no lograr la pretendida solución y perpetuarse el fracaso escolar, la institución educativa busca nuevos destinos para esa infancia diversa. Se fragmenta así la oferta educativa de múltiples formas, entre las que destacamos: escuela común/escuela especial, o múltiples formas de transitar por la escuela común: jornada completa/jornada reducida, semana completa/algunos días de la semana, o escolaridad compartida algunos días de la semana en escuela 
común/algunos días de la semana en escuela especial, condicionamientos para la asistencia ligados a la medicación con psicofármacos o al acompañamiento terapéutico, entre otros.

Es decir que la derivación a un equipo técnico aparece como el primer movimiento que hace la escuela, derivación que se resuelve, en la inmensa mayoría de los casos, con un diagnóstico psicopatológico de corte individual. Como segundo movimiento en respuesta al poder simbólico totalizante del diagnóstico, la escuela ofrece tránsitos educativos alternativos a la escuela común o tránsitos alternativos en la misma escuela común, alejando, en general, la búsqueda de posibilidades en el marco del vínculo pedagógico.

El énfasis casi exclusivo en la dimensión descriptiva de los diagnósticos clasificatorios debilita la comprensión dinámica del conjunto de vicisitudes y circunstancias que es efecto de determinadas condiciones concretas de vida. El diagnóstico termina siendo, en la mayoría de los casos, la atribución de un conjunto de características definidas previamente como diferencias, y que ubican a la persona dentro de una categoría y determina, de alguna manera, lo que es (más bien lo que no es) y lo que se puede o no esperar de ella. Los diagnósticos operan, entonces, prenocionando cualquier encuentro posible, impulsan posicionamientos subjetivos a partir de lo que falta, de lo que no se tiene o de lo que no se es.

Los adjetivos, los diagnósticos con los que se clasifican a niños y niñas actúan a modo de anticipación o predicción del comportamiento y del rendimiento efectivo. Cuando estos diagnósticos son enunciados en el contexto de una relación de poder (maestro/a-alumno/a) y por quien lo ostenta, se incrementa la posibilidad de que el comportamiento y rendimiento esperados de hecho ocurran, efecto del poder simbólico de la palabra sobre la constitución subjetiva. Al respecto, plantea Vasen (2012):

Creo importante tener en cuenta tanto en las escuelas como en la consulta que clasificar es en rigor una técnica que se guía por lo aparente y agrupa los fenómenos que objetiva en una serie. Una clasificación se funda en una selección de datos. Subrayo el término pues no hay categorías ni clases naturales, sino construcciones. Es esa selección la que deriva en la construcción de un dato que es un abrochamiento unívoco entre un "hecho" y su significado. Esa objetivación deja de lado que los datos están ordenados desde el imaginario y los discursos científicos (siempre relativos) de cada época. 0 sea algo es apropiado como dato y convertido en signo de una información que, aparentemente, no requiere desciframiento. (p. 151-152)

Podríamos agregar que, además de no requerir desciframiento porque el sentido es absoluto, corre del análisis de los problemas en el aprender al vínculo pedagógico, que se establece en una relación singular, en un contexto institucional también singular. Los obstáculos para aprender son siempre cuestión de niños y niñas y, en general, el lugar de los adultos y de las adultas continúa sin ser interpelado.

Por otro lado, la perspectiva institucional parte de la premisa de que el aumento de la inversión presupuestal en el sistema educativo permitirá ofrecer una educación de calidad que oficiará como generadora de igualdad. No dudamos de la urgencia de realizar inversiones 
responsables en el sistema educativo, en todos sus niveles. Lo que intentamos poner en discusión aquí es cómo esta premisa ubica estrictamente en la institución educativa la responsabilidad y la posibilidad efectiva de un cambio social, bajo la premisa de que la escuela es una institución capaz de revertir las condiciones estructurales que explican la distribución desigual del capital material y simbólico en la sociedad. Al respecto, dice Dubet (2016):

A pesar de la democratización del acceso a los estudios, las desigualdades sociales siguen teniendo peso en la trayectoria de los alumnos. Ricos y pobres, burgueses y obreros no cursan los mismos estudios, y, al cabo de estos, los "vencedores" y los "vencidos" de la selección escolar se distribuyen siempre en función de sus orígenes sociales. (...) En el fondo, mientras haya desigualdades sociales, la escuela no podrá sino reflejarlas y reproducirlas de generación en generación. (p. 30)

En la misma línea, Corea (2011) señala:

En tiempos estatales, cuando hay Estado, cuando hay estabilidad, solidez, cuando hay reproducción regular de insumos, de dispositivos, de prácticas, las subjetividades producidas en cada institución, los discursos y las posiciones de enunciación son equivalentes. (...) Esta organización, que podríamos Ilamar organización en lo sólido, y en condiciones regulares, ha estallado. Entonces, en la medida que el Estado estalla en esta capacidad lógica de cohesionar o de coordinar, las instituciones devienen fragmentos e islotes. (p. 65)

Estas palabras de Corea resultan de gran valor para dar sentido a crecientes desencuentros entre la escuela y la familia, -y agregaremos nosotras- entre la escuela y el saber técnico profesional.

La escuela se presenta, a modo declarativo, con la potencialidad de ser generadora de igualdad, no obstante, en un marco social caracterizado por profundas e injustas desigualdades que se expresan, entre otras cosas, en las diferencias significativas en los tránsitos educativos de niños y niñas en función del quintil de ingresos al cual pertenecen, esa potencialidad queda elidida.

\section{La pretensión igualadora de la escuela moderna}

En la génesis de la escuela, es posible identificar el denominado pacto fundacional mediante el cual las familias delegaron en el Estado, y este en la escuela, la responsabilidad de la educación. Este dispositivo de educación masivo se convirtió en una promesa: la de ser la herramienta que posibilitaría la igualdad a partir de generar movimientos ascendentes a través de la escala social (Vain, 2009).

Sin embargo, Modernidad y capitalismo mediante, la escuela no ha cumplido con la promesa inicial de conquista de la igualdad social. De hecho, no solo no ha cumplido con esta promesa, sino que se ha transformado en legitimadora de las diferencias sociales, en tanto las reproduce, jugando un papel central en la distribución de los sujetos en el mundo laboral, 
facilitando u obturando el acceso a partir de los logros académicos. En este sentido, Bourdieu (2018) señala que:

La reproducción de las relaciones de clase, en realidad, es también el resultado de una acción pedagógica que no parte de una tabula rasa, sino que se ejerce sobre los sujetos que recibieron de su familia o de las acciones pedagógicas procedentes (es decir, la llamada "educación primera") por un lado cierto capital cultural y por el otro un conjunto de posturas con respecto a la cultura. (p. 17)

Así, el autor critica la narrativa que ubica a la escuela como una institución objetiva y neutra, que asegura el ascenso social de todas las personas con independencia de su origen, y plantea que el desempeño académico está sostenido e influenciado por una serie de adquisiciones culturales que anteceden el ingreso a la etapa escolar y por una cierta valoración respecto de la cultura, ambas dependientes de la clase social a la que pertenezca el individuo. La escuela contribuye así a reproducir la distribución del capital social y a perpetuar determinada estructura social, que favorece a las clases dominantes.

La familiaridad nos impide ver lo que esconden los actos en apariencia puramente técnicos que lleva a cabo la institución escolar. (...) En todas las sociedades avanzadas, en Francia, en Estados Unidos o en Japón, el éxito social depende muy estrechamente de un acto de nominación inicial (la imposición de un nombre, de ordinario el de una institución educativa, Universidad de Todai o de Harvard, Escuela Politécnica) que consagra escolarmente una diferencia social preexistente. La entrega de diplomas, que da lugar a ceremonias solemnes, es efectivamente comparable al acto de armar caballero a alguien. La función técnica evidente, demasiado evidente, de formación, de transmisión de una competencia técnica y de selección de los más competentes técnicamente, enmascara una función social, a saber, la consagración de los detentores estatutarios de la competencia social, del derecho a dirigir. (Bourdieu, 2005, p. 112-113)

¿Cómo podemos explicar el fracaso de la institución educativa en su intención original de ser garante de igualdad social? De acuerdo con Viscardi y Habiaga (2017): "Históricamente, la función integradora de la educación en tanto canal de movilidad social contribuyó a consolidar las clases medias. Pero la ausencia de correlato en la expansión económica terminó con esta tendencia" (p. 129).

Quizás corresponde cuestionar que sea la escuela quien deba asumir esta compleja empresa. Así, consideramos que la escuela se arroga una responsabilidad, un mandato social que contradice parte de su esencia: la de contribuir a perpetuar un orden social funcional a un sistema productivo. Orden social que, en nuestro país, se caracteriza por profundas desigualdades en la distribución del capital económico, social y simbólico.

La inequidad precede al ingreso escolar, y es claro que el peso de las condiciones de arribo a la institución educativa no puede ser desconocido ni subestimado, en tanto se vincula fuertemente con las posibilidades de éxito. Al respecto, dirá Gentili (2012): "La inclusión es un 
proceso democrático integral que involucra la superación efectiva de las condiciones políticas, económicas, sociales y culturales que producen históricamente la exclusión" (p. 80).

El sistema educativo se presenta en apariencia igualitario, sin embargo, opera con un alto grado de segmentación, ofreciendo dispares propuestas, según los sectores sociales que atiende, transformándose, entonces, en un sistema de reproducción de lugares. Esta reproducción es tanto simbólica como material, pues emana de la convivencia de propuestas educativas claramente diferenciadas (escuela pública en sus múltiples formatos: común, de contexto crítico, escuela especial, colegios privados, etc.). En palabras de Bordoli y Martinis (2010): "es posible distinguir circuitos diferenciales en relación a la especificidad de lo educativo y en los procesos de distribución del capital cultural" (p. 232).

Al igual que el resto de las instituciones que forman parte de la sociedad, la institución escolar surge en respuesta a una necesidad planteada en un contexto histórico, social y político particular. De acuerdo con Contreras Domingo (1994), en la génesis de la escuela, se reconoce la influencia de dos grandes acontecimientos:

I. La revolución francesa, inaugurando un nuevo orden político y social, por el cual los hombres dejaron de ser súbditos del rey para transformarse en ciudadanos de una República.

II. La primera revolución industrial, determinando el posterior apogeo y expansión del capitalismo con la consecuente necesidad de garantizar la capacitación de trabajadores funcionales al sistema, que soporten una forma de producción basada en la especialización y la división del trabajo: mano de obra con una instrucción elemental y mínima calificación, tendiente a asegurar altos niveles de productividad.

La escuela se erige, así, como una institución capaz de sostener este nuevo orden político y social, asegurando la transmisión y control de los valores y principios de la sociedad impuestos desde los sectores hegemónicos. Autores como Durkheim (1999) y Parsons (1959) les han adjudicado a las instituciones escolares un importante papel vinculado al control social y a la asignación de roles dentro de la sociedad. Señalan que, partiendo de la igualdad de oportunidades y de una idéntica accesibilidad a los contenidos educativos, los sujetos se diferencian exclusivamente en función de variables adquiridas (desempeño educativo), y no por variables inherentes al sujeto o a la situación en la que se encuentra (estatus socioeconómico, sexo, lugar de nacimiento), y que existe, además, una conexión lineal entre resultados escolares y la posición en la estructura laboral. Entendemos que esta perspectiva desconoce la relación que existe entre las condiciones concretas de existencia de la persona y los logros académicos, en el sentido de que las primeras determinan fuertemente las segundas.

A partir de la década del setenta del siglo pasado, emergen actores, desde el campo de las ciencias sociales, que denuncian el fracaso de la educación como mecanismo efectivo de distribución social. Los Estados responden a esta situación ubicando las causas del fracaso en la escuela. Surgen, así, discursos vinculados a la asignación de mayores recursos económicos para la educación, en el entendido de que la escuela continuaba siendo la herramienta privilegiada a 
través de la cual se podía aspirar a la movilidad e igualdad social. Desde esta perspectiva, el fortalecimiento de la institución educativa sería el garante del éxito escolar y, posteriormente, del éxito social (Labraña, 2012).

Sin embargo, contrario a estos supuestos, el Informe Coleman (1966) ubica la explicación de la correspondencia entre clase social y resultados académicos en aspectos culturales propios de las personas y sus familias, y no en cualidades de la escuela a la que asistían.

Más adelante, la denominada teoría crítica de la educación niega la concepción de un sistema educativo neutral, y destaca la función de la educación en el mantenimiento de las diferencias entre las clases sociales. Desde esta teoría, el sistema educativo se organiza de modo de perpetuar el arreglo de clases predominante en la sociedad y, por lo tanto, el fenómeno de la desigualdad no es consecuencia de una imperfección en su funcionamiento, sino más bien su objetivo (Morales Zúñiga, 2014).

Desde otra perspectiva, Althusser (1985) introduce el concepto de aparato ideológico del Estado. Escuela, iglesia y familia se presentan como ámbitos privilegiados de imposición de la ideología hegemónica, legitimando como naturales las desigualdades injustas entre clases sociales.

Convive, junto a los enfoques antes descritos, una visión tecnocrática que concibe a los aparatos educativos como el espacio privilegiado para actuar sobre la desigualdad en la sociedad. A partir de análisis económicos, se promueve el desarrollo de políticas públicas, incorporando una concepción de la educación entendida como una inversión. Desde esta visión, se destinan mayores recursos al sistema educativo y se mejoran las condiciones de la educación, esperando obtener una rentabilidad específica (Bonal, 1998).

En síntesis, la escuela surge a nivel declarativo como una institución revolucionaria capaz de generar un orden social distinto y potencialmente igualador. Sin embargo, diferentes corrientes y pensadores han visibilizado la tensión latente entre dos mandatos contrapuestos: por un lado, operar transformaciones tendientes a modificar el orden económico y social establecido y, por el otro, perpetuarlo.

Entendemos que el sistema educativo no es un aparato neutro, y su funcionamiento favorece de manera sistemática a los individuos provenientes de familias mejor ubicadas en la escala social y relega a aquellos provenientes de familias de menores recursos. De hecho, en Uruguay, el fracaso y la deserción escolar se concentran en la infancia en situación de pobreza, afrodescendiente y la que reside en el medio rural (Organización de Naciones Unidas, 2017). Parecería ser que, en el sistema educativo actual, las "desigualdades de cuna" se mantienen en la escuela, y no a pesar de ella, escenario en el que continuaríamos reconociendo un potencial igualador a la institución, que ha sido, en todo caso, poco eficaz. 


\section{Igualdad, homogeneización, diversidad: nociones que conviven y moldean la comprensión y la intervención en el campo del fracaso escolar}

Uno de los primeros conceptos que proponemos problematizar en el contexto educativo actual es el de la pretendida igualdad como supuesto efecto del tránsito por una institución educativa de calidad. El discurso de los derechos humanos jerarquiza los planteamientos vinculados a la igualdad. Esta igualdad proclamada a nivel de derechos parece no encontrar su correlato en los hechos, y esta brecha es producto de la existencia de una inequidad social de base.

Nos preguntamos: ¿la educación de calidad puede operar neutralizando los efectos de la inequidad que se expresan en tránsitos educativos signados por el fracaso? A nivel imaginario, pareciera ser que la educación de calidad ofrece un marco de oportunidades que podría ser capitalizado por los niños y las niñas que por allí transitan, sin excepción, efecto de la potencia igualadora de la escuela.

La aspiración a la igualdad ha estado presente desde el origen de la escuela. La expansión del sistema educativo moderno fue posible gracias a la escolarización masiva, en cuya base se encuentra la gratuidad y la obligatoriedad. La imagen de niños y niñas provenientes de diferentes estratos de la sociedad compartiendo el mismo salón de clase y recibiendo la misma educación ha sido motivo de orgullo para muchas generaciones de nuestro país.

La igualdad representa un ideal construido socialmente, conformado por una serie de imágenes y representaciones que se traducen en un conjunto de características a las que niños y niñas deben acercarse. En el caso de la escuela, un ideal construido por la institución que, en nombre de este valor incontrovertible, de esta aspiración abstracta que es la igualdad, homogeniza contenidos, objetivos y procesos, intentando mitigar o borrar las diferencias.

Así, detrás del discurso de la igualdad, se impuso un proceso de fuerte homogeneización que implicó privilegiar la adquisición de determinados comportamientos y desempeños normalizados, neutralizando las diferencias y desalentando cualquier desviación.

La igualdad se traduce, concretamente en la experiencia escolar, a través de las siguientes pretensiones: una igualdad de inicio, por la cual se conforman grupos homogéneos (mismo punto de partida); una igualdad de contenidos, por la cual se les presenta a niños y niñas lo mismo, sin excepciones; una igualdad de proceso, por la cual se les trata a todos y todas de la misma manera, independientemente de las necesidades particulares; y una igualdad de llegada, por la que se esperan los mismos resultados o metas para el conjunto del alumnado (Contreras Domingo, 2011).

De esta manera, la escuela pretende la construcción de una identidad relativamente homogénea entre niños y niñas, vehiculizando valores culturales, sociales y cívicos. Se vale, para ello, de la transmisión de una historia oficial, de la utilización de símbolos patrios y de la imposición de los rasgos más distintivos de la cultura dominante. Quedan poco representados diversos grupos que no encuentran, en esta institución, un lugar para su expresión: personas en situación de pobreza, personas en situación de discapacidad, migrantes, etc. En definitiva, esta 
insistencia por la igualdad resalta las dificultades que presenta la institución escolar para reconocer y alojar la singularidad.

Aceptar al sujeto en su singularidad, en su historia, con sus conflictos, intereses y motivaciones, supone cierta disposición, implica suspender o silenciar, al menos de cierto modo, el juicio y las ideas previas, en el sentido de supuestos que anticipan una forma de vínculo con tal o cual población (por ejemplo, en lo que refiere a las personas en situación de discapacidad).

La dificultad de la escuela en reconocer la singularidad se traduce de múltiples formas, una práctica concreta es la derivación de "lo diverso" desde el sistema educativo hacia el sistema sanitario para su diagnóstico y tratamiento, en el entendido de que constituye una alteración. Estas derivaciones se han ido multiplicando en los últimos tiempos. Parece ser que, lo que la escuela no puede igualar, lo podrá hacer el saber técnico-profesional (Cristóforo y Achard, 2017).

Se construye, así, un vínculo muy particular entre el sistema educativo y el sanitario de formulación de demandas cruzadas en relación con la elaboración de respuestas asertivas para el fracaso escolar. No obstante, a su vez, los actores de ambos sistemas conviven con la idea de que lo realizado, en un gran número de situaciones, resulta fútil; la desigualdad en los resultados persiste y las demandas no se logran reformular. Podríamos pensar, entonces, en una igualdad homogeneizante que, cuando fracasa, acciona mecanismos de exclusión.

Por otra parte, el término diversidad, de reciente ingreso al escenario educativo, resuena cada vez con más potencia, asociado a los discursos que pregonan la inclusión. Sin embargo, debemos analizar cuidadosamente el sentido que adquiere la noción de diversidad, en especial a quiénes se incluyen dentro de esta categoría. Nos preguntamos, entonces: ¿los que fracasan son los diversos y las diversas?, ¿la diversidad se presenta como eufemismo del fracaso escolar?

La diversidad de los atributos humanos, naturales y sociales de distintos grupos de una sociedad es una característica consustancial de la vida humana y se materializa en procesos como los de diferenciación de género, étnicos y culturales. Los distintos géneros, etnias y grupos de edad que hacen parte de la diversidad surgen de diferencias biológicas, como el sexo, la raza y la edad biológica, alrededor de las cuales se dan construcciones culturales y de poder (Breilh, 2009).

Podemos pensar, entonces, que la diversidad recorre todo el universo escolar porque, siguiendo a Breilh, si hay algo que define al ser humano es lo variopinto de las características e historias personales, que son expresión de su riqueza. Sin embargo, en el contexto educativo, el término diversidad se utiliza en otro sentido: refiere exclusiva y excluyentemente a grupos de niños, niñas y adolescentes que portan ciertas características que los alejan de esta invención social que es la norma, concepto difuso que califica negativamente todo lo que excluye.

Kachinovsky (2012) dice al respecto: "Es tan diverso lo humano como las formas de exclusión posibles, y son muy magros los resultados de las prácticas inclusivas aisladas cuando la institución funciona con una lógica excluyente" (p. 29).

Encontramos, así, un conjunto siempre indeterminado e impreciso de características que definen a las personas como diferentes, y una marcada tendencia a establecer una equivalencia entre diversidad y alteridad, en tanto diverso es siempre el otro que asume, según el caso, 
diferentes cuerpos, colores, olores, nombres, etiquetas. A nivel imaginario, la diversidad es considerada, en el marco escolar, como un problema, una situación que se desvía de la norma y que fisura la homogeneidad, y debe, por tanto, recibir un tratamiento especial: surge así la denominada atención a la diversidad.

En este sentido, el término diversidad adquiere una connotación negativa y se asocia con relativa insistencia a discapacidad, dificultades de aprendizaje, fracaso escolar y con un más o menos extenso etcétera dentro del cual encontraríamos: identidad de género, raza/etnia, franja etaria, clase social, entre otros.

De los múltiples grupos catalogados como "diversos", nos centramos, aquí, en los que configuran fracaso escolar. La institución educativa se ha organizado históricamente en función de una serie de supuestos; en particular, destacamos: la conformación de grupos de niños y niñas homogéneos y el desarrollo de estrategias de enseñanza que tienden a normalizar en materia de resultados. Aquellos niños y niñas que no logran cumplir con estos criterios de normalidad integran alguno de los múltiples grupos que configuran el terreno de lo diverso. La institución educativa desarrolla, entonces, una serie de estrategias de abordaje.

Así, la escuela acumula una larga tradición en la llamada atención a la diversidad, la pregunta que cabe formular es acerca de las características de esa atención, sus implicancias y sus efectos. Las políticas inclusivas responden a las demandas generadas por procesos de exclusión más o menos profundos y explícitos, y su formulación debiera implicar fuertemente la deconstrucción de los supuestos que sostienen la exclusión, en el entendido de que el fenómeno de la exclusión es en sí una construcción sociohistórica que opera en cada espacio-tiempo con lógicas distintas.

Skliar (2017) reconoce la importancia de visibilizar los problemas que la exclusión y la inequidad implica para amplios sectores de la sociedad. Aun así, señala que los desafíos a los que nos enfrentamos como sociedad en la actualidad son diferentes y los sintetiza en cuatro puntos:

Que se abran de verdad, incondicionalmente, las puertas de las escuelas públicas a los niños y jóvenes mal entendidos como "diferentes"; que el lenguaje del derecho no se enquiste apenas en una estructura político-formal sino en una ética de las relaciones -una ética singular, una ética de la responsabilidad, de la afección-; que la organización de las escuelas modifique sus espacios y sus tiempos no ya en virtud de las pautas evaluativas externas sino en consideración de las particularidades de la vida interna de las comunidades escolares y que las prácticas educativas se concentren en una idea del enseñar a "cualquiera", desprendiéndose de toda idea de normalidad y control sobre el aprendizaje. (p. 45)

En este sentido, entendemos que apelar al discurso de la atención a la diversidad no es la solución en tanto no responde a una nueva mirada sobre las dificultades vinculadas a la inserción escolar, sino a la legitimación institucional de los diagnósticos clasificatorios. 


\section{Consideraciones finales}

Como profesionales de la salud que intervienen en el ámbito educativo, resulta fundamental interrogarnos por las conceptualizaciones y teorías que sostienen nuestra praxis, estar atentos y atentas a los intersticios por los que se cuelan los discursos dominantes en nuestras prácticas cotidianas.

La potencia igualadora de la escuela se encuentra muy arraigada en los discursos educativos y en el imaginario uruguayo, sin embargo, la evidencia empírica muestra que el nacer y crecer en contextos de pobreza determina, en gran medida, los modos de transitar por la escuela, prevaleciendo el rezago y el fracaso escolar en niños y niñas pobres.

Algunos discursos vinculados al problema del fracaso escolar destacan la apoyatura neurobiológica de los procesos de aprendizaje, por lo que la lectura de sus alteraciones se corresponde con perspectivas biológicas que profundizan los procesos de medicalización de la infancia y de patologización de ciertas diferencias. En palabras del Grupo de trabajo en medicalización y patologización de las infancias y adolescencias de la Institución Nacional de Derechos Humanos y Defensoría del Pueblo (2019) de nuestro país:

Sin desconocer la existencia de prácticas promotoras de salud, las lógicas pedagógicas quedarían supeditadas a las lógicas médicas, en una sociedad uruguaya históricamente medicalizada y medicalizadora. Así, aprender o no aprender son fenómenos que terminan siendo direccionados como individuales; es decir, es el niño/a o adolescente es el último responsable de su aprendizaje o de su fracaso, siendo la institución educativa o los formatos escolares pocas veces interrogados. (p. 33-34)

Es central, entonces, problematizar el fracaso escolar y ubicar la expresión en lo singular de complejos procesos sociales, económicos y políticos. Es necesario deconstruir los supuestos que subyacen a la categorización de este fenómeno y analizar cómo se traducen estos supuestos en el diseño y la implementación de las políticas educativas inclusivas. Al respecto, Kachinovsky (2012) plantea que:

Los procesos de recuperación democrática que tuvieron lugar en muchos países de la región en las últimas décadas, se acompañaron de una vasta reflexión sobre el fracaso escolar. La estrecha relación entre desventaja escolar y desventaja social priorizó nuevos derroteros; la mirada comenzó a volcarse entonces sobre la desigualdad social. (p. 28) El fracaso escolar, como campo multidimensional complejo, es objeto de estudio de diversas disciplinas que construyen, a efectos de su abordaje, diferentes marcos conceptuales y estrategias de intervención. La red de relaciones de poder en la que se sostienen los discursos disciplinares acentúa el peso de la perspectiva medicalizante. Es por esto que intentamos recuperar, en esta oportunidad, el valor etimológico de la palabra "diagnóstico", vinculado al discernimiento, lo que nos permite insistir en el valor del diagnóstico situacional, que opere posibilitando el sentido y no obturándolo. Los diagnósticos psicopatológicos individuales, que recaen cada vez con mayor frecuencia en niños y niñas vulnerados y vulneradas en sus derechos, invisibilizan que la fragilidad de las herramientas del aprender deviene de la imbricación de 
aspectos del contexto social, económico y político con aspectos individuales. Al decir de Dabas (1998):

En esta época de mutación y cambio, a pesar de todas las reformas, la escuela está intocada en lo esencial. (...) Los elementos fundamentales, estructurales son los mismos desde su fundación aunque el sistema social plantee otras necesidades. El sistema educativo moderno nació para reproducir lo que la Iglesia no podía hacer plenamente. Con las migraciones masivas a las ciudades, las familias y sobre todo los niños perdieron el hábitat rural acogedor, pasando a vivir en un ambiente degradado. (...) Para atenuar esta situación y dado que la Iglesia por sí sola no podía afrontar el cuidado de los menores, se crean las escuelas comenzando el Estado a tener influencia en la educación. Se crea así un sistema destinado a adaptar a los jóvenes al mundo social vigente. (p. 33) Consideramos que el camino que debe recorrer el sistema educativo para incluir las diferencias no es el de forzar la impregnación en la institución de un discurso inclusivo, ya que la evidencia muestra que ha resultado extremadamente difícil trascender el plano meramente declarativo. Sin duda que es indudable el valor ético de las declaraciones, sin embargo, las prácticas cotidianas no se ven sustancialmente permeadas por ellas. Rescatamos, entonces, la importancia de la deconstrucción como movimiento que permite ir ubicando los dogmas que dominan el escenario educativo y que alejan toda posibilidad genuina de inclusión.

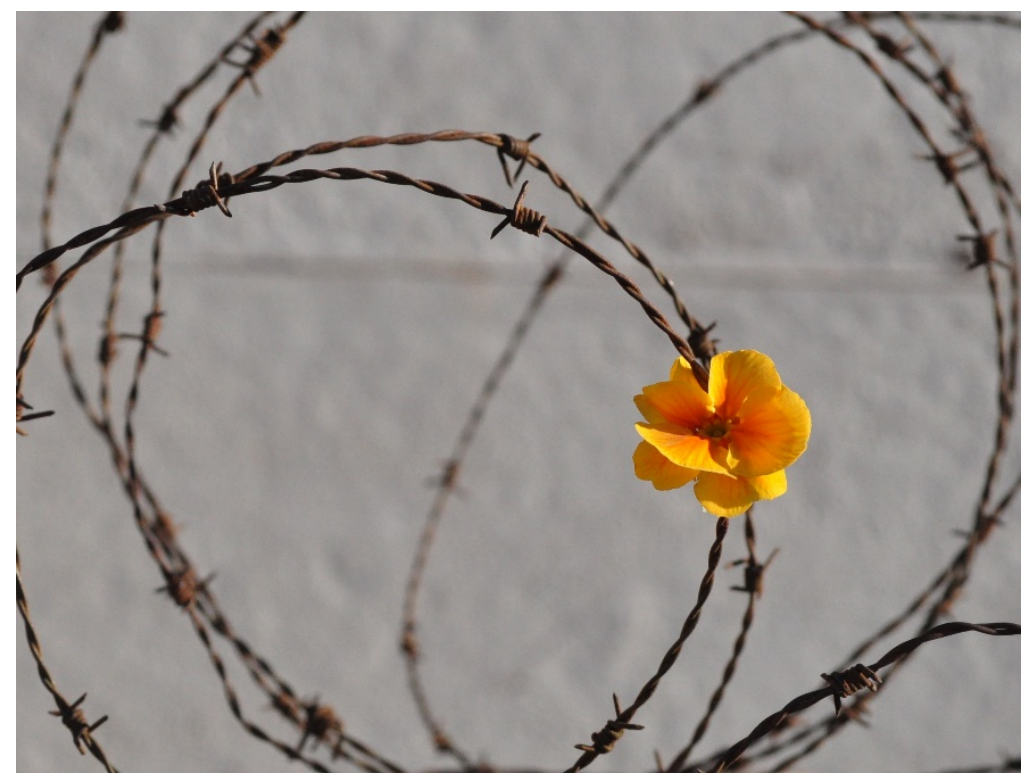

Genocidio y sobrevivencia, fotografía. Alejandro Urioste 


\section{Bibliografía}

Althusser, L. (1985). El aparato ideológico del estado escolar como aparato dominante. En A. Gras (Comp.), Sociología de la educación: textos fundamentales. Narcea.

Anderete Schwal, M. (2020). Las desigualdades educativas durante la pandemia en la educación primaria de Argentina. Revista Andina De Educación, 4(1), 5-10. https://doi.org/10.32719/26312816.2021.4.1.1

Aristimuño, A. (2015). El fracaso escolar, ¿fracaso de quién? La modificación del concepto de fracaso. Revista Latinoamericana de Educación Inclusiva, 9, (1), 111-126.

Bonal, X. (1998). Sociología de la educación. Una aproximación crítica a las corrientes contemporáneas.

Paidós.

Bordoli, E. y Martinis, P. (2010). Relaciones entre educación y pobreza. Continuidades y rupturas del discurso moderno. En M. Serna (Coord.), Pobreza y (des)igualdad en Uruguay: una relación en debate. (pp. 227-240). Universidad de la República. Consejo Latinoamericano de Ciencias Sociales.

Bourdieu, P. y Passeron, J. (2018). La reproducción. Siglo XXI.

Bourdieu, P. (2005). Capital cultural, escuela y espacio social. Siglo XXI.

Breilh, J. (2009). Epidemiología crítica. Lugar Editorial.

CEPAL y UNESCO. (2020). Informe COVID-19 CEPAL-UNESCO. La educación en tiempos de la pandemia de COVID-19. https://repositorio.cepal.org/bitstream/handle/11362/45904/1/S2000510_es.pdf

Coleman, J. (1966). Equality of educational theory. Office of Education.

Contreras Domingo, J. (2011). Percibir la singularidad, y también las posibilidades, en las relaciones educativas ¿Una pedagogía de la singularidad? Diploma superior "Pedagogía de las diferencias". FLACSO.

Contreras Domingo, J. (1994). Enseñanza, currículum y profesorado. Akal.

Corea, C. y Lewkowicz, I. (2011). Pedagogía del aburrido. Escuelas destituidas, familias perplejas. Paidós.

Cristóforo, A. y Achard, P. (2017). Efectos de desubjetivación de los diagnósticos psi de los adolescentes en la educación. En P. Martinis, M. Miguez, N. Viscardi y A. Cristóforo (Coords.), Derecho a la educación y mandato de obligatoriedad en la Enseñanza Media. La igualdad en cuestión. (pp. 223-260). Comisión Sectorial de Investigación Científica, Universidad de la República.

Dabas, E. (1998). Redes sociales, familia y escuela. Paidós.

Dubet, F. (2016). ¿ ¿Por qué preferimos la desigualdad? Siglo XXI.

Durkheim, É. (1999). Educación y sociología. Altaya. S. A.

Dussel, I., Ferrante, P. y Pulfer, D. (2020). Pensar la educación en tiempos de pandemia: entre la emergencia, el compromiso y la espera. UNIPE.

Escudero Muñoz, J. M. (2005). Fracaso escolar, exclusión educativa: ¿De qué se excluye y cómo? Profesorado, revista de currículum y formación de profesorado, 7(1), 1-24. http://libro.ugr.es/bitstream-

/10481/15197/1/rev91ART1.pdf

Freire, P. (2011). La educación como práctica de la libertad. Siglo XXI Editores.

Gentili, P. (2012). Pedagogía de la igualdad. Ensayos contra la educación excluyente. Siglo XXI Editores.

Grupo de trabajo medicalización y patologización de las infancias y adolescencias. Institución Nacional de Derechos Humanos y Defensoría del Pueblo-Uruguay. (2019). Medicalización y patologización de las infancias y las adolescencias. https://psico.edu.uy/sites/default/pub_files/2019-

12/Medicalizaci\%C3\%B3n\%20de\%20la\%20infancia_ctapa-1.pdf

Kachinovsky, A. y Gabbiani, B. (Coords.). (2014). Una alternativa al fracaso escolar. Hablemos de buenas prácticas. Ediciones Universitarias. 
Kachinovsky, A. (2012). Enigmas del saber. Historias de aprendices. Montevideo: Biblioteca Plural. Ediciones Universitarias.

Labraña, J. (2012). La educación como garantía de igualdad o desigualdad en la sociedad moderna: Observaciones desde la teoría de sistemas sociales. Revista Mad-Universidad de Chile, (26), 17-33.

www.revistamad.uchile.cl

Lara-García, B., González-Palacios, A., González-Álvarez, M. A. y Martínez-González, M. G. (2014). Fracaso escolar: conceptualización y perspectivas de estudio. Revista de Educación y Desarrollo, 30, 71-83. Mafokozi, J. (1991). Evaluación y fracaso escolar: la perspectiva del alumno. Revista Complutense de Educación, 2(2), 171-194.

Morales Zúñiga, L. C. (2014). El pensamiento crítico en la teoría contemporánea. Revista Electrónica: Actualidades Investigativas en Educación, 14(2), 1-23. http://www.scielo.sa.cr/pdf/aie/v14n2/a20v14n2.pdf Organización de Naciones Unidas. (2017). Observaciones del Comité de los Derechos del Niño sobre los informes periódicos presentados por Uruguay. 2007 y 2015.

https://pmb.aticounicef.org.uy/opac_css/doc_num.php?explnum_id=174

Parsons, T. (1959). The School Class as a Social System: Some of its Functions in American Society. Harvard Educational Review, 29(4), 297-318.

Rancière, J. (2007). El maestro ignorante. Cinco lecciones sobre la emancipación intelectual. Libros del Zorzal. Rebollo, M. (2007). El desarrollo neuropsíquico y su evaluación. Prensa Médica Latinoamericana.

Skliar, C. (2017). Pedagogías de las diferencias. Noveduc.

Terigi, F. (2009). El fracaso escolar desde la perspectiva psicoeducativa: hacia una reconceptualización situacional. Revista Iberoamericana de Educación, 50, 23-39.

Uruguay. ANEP. (2021). Monitor educativo de enseñanza primaria. Estado de situación 2020. CEIPDepartamento de Estadística Educativa.

https://www.anep.edu.uy/monitorRepo/Documentos\%202020/ESTAD0\%20DE\%20SITUACION\%202020\%2 027_4\%20final.pdf

Vain, P. (2009). Escuela, Estado y familia. Un pacto por redefinir. Educación, Lenguaje y Sociedad, V/(6), 329344.

Vasen, J. (2012). El asesinato del alma. En A. Taborda, G. Leoz y G. Dueñas (Comps.), Paradojas que habitan las instituciones educativas en tiempo de fluidez (pp. 143-165). Nueva Editorial Universitaria.

Viscardi, N. y Habiaga, V. (2017). El derecho a la educación en disputa: dinámicas de resistencia y dinámicas de exclusión. En P. Martinis, M. Miguez, N. Viscardi y A. Cristóforo (Coords.), Derecho a la educación y mandato de obligatoriedad en la Enseñanza Media. La igualdad en cuestión. (pp. 101-166). Comisión Sectorial de Investigación Científica, Universidad de la República. 